\title{
Business Cycles, Bifurcations and Chaos in a Neo-Classical Model with Investment Dynamics
}

\author{
Stéphane Hallegatte ${ }^{\mathrm{a}, \mathrm{b}}$, Michael Ghil ${ }^{\mathrm{c}, \mathrm{d}}$, Patrice Dumas ${ }^{\mathrm{a}, \mathrm{c}}$, \\ Jean-Charles Hourcade ${ }^{a}$, \\ ${ }^{a}$ Centre International de Recherche sur l'Environnement et le Développement, \\ Nogent-sur-Marne, France \\ ${ }^{\mathrm{b}}$ Center for Environmental Sciences and Policy, Stanford, USA \\ ${ }^{\mathrm{c}}$ Département Terre-Océan-Atmosphère and Environmental Research and Teaching \\ Institute, Ecole Normale Supérieure, Paris, France \\ ${ }^{\mathrm{d}}$ Department of Atmospheric and Oceanic Sciences and Institute of Geophysics and \\ Planetary Physics, University of California, Los Angeles, CA 90095-1565, USA
}

\begin{abstract}
This paper is motivated by the rising interest in assessing the effect of disruptions in resources and environmental conditions on economic growth. Such an assessment requires, ultimately, the use of truly integrated models of the climate and economic systems. For these purposes, we have developed a Non-Equilibrium Dynamic Model (NEDyM) by introducing investment dynamics and nonequilibrium effects into a Solow growth model. NEDyM can reproduce various economic regimes, such as manager- or shareholder-driven economies, and permits one to examine the effects of disruptions on the economy, given either an assumption of steady-state growth or an assumption of business cycles with transient disequilibrium. We have applied NEDyM to an idealized economy that resembles in certain respects the 15-state European Union in 2001.

The key parameter in NEDyM is investment flexibility. For certain values of this parameter, the model reproduces classical business cycles with realistic characteristics; in particular, NEDyM captures the cycles' asymmetry, with a longer growth phase and more rapid contraction. The cyclical behavior is due to the investmentprofit instability and is constrained by the increase in labor costs and the inertia of production capacity. For somewhat greater investment flexibility, the model exhibits chaotic behavior, because a new constraint intervenes, namely limited investment capacity. The preliminary results presented here show that complex behavior in the economic system may be due entirely, or at least largely, to deterministic, intrinsic factors, even if the economic long-term equilibrium is neo-classical in nature. In the chaotic regime, moreover, slight shocks - such as those due to natural or man-made catastrophes - may lead to significant changes in the economic system.
\end{abstract}

Preprint submitted to Elsevier Science 8 May 2006 
Key words: Macroeconomic dynamics, Nonequilibrium modeling, Business cycles, Investment flexibility

\section{Introduction and motivation}

This paper introduces a modeling framework for macroeconomic growth dynamics that is motivated by recent attempts to formulate and study "integrated models" of the coupling between natural and socio-economic phenomena. These attempts are driven, at least in part, by public debate about global issues, such as anthropogenic climate change. The challenge is to describe the interfaces between human activities and the functioning of the earth system over the very long term. In this context, economists have used primarily longterm growth models in the Solow tradition, relying on the idea that, over time scales of decades to centuries, the golden-age paradigm is an acceptable metaphor.

This approach appears, however, to be increasingly at variance with the nature of the policy debates in the field. Advocates of stringent emission limits are concerned about the cost of damages caused by climate change, while their opponents worry about the cost of greenhouse gas abatement. But balanced growth models that incorporate many sources of flexibility tend to suggest that the damages caused by disruptions of the natural - i.e., physical and biological - planetary systems, as well as the mitigation policies proposed to prevent these disruptions, will entail only "a few percent" of losses in gross domestic product (GDP) over this century (IPCC, 2001). Both categories of activists tend thus to suspect that the figures suggested by current models underestimate either type of costs, since real economies rarely manifest a tendency to steady-state behavior.

The core debate in macroeconomics used to be whether governments could control business cycles in an efficient manner by manipulating fiscal and monetary policy. Instead, the focus here is on whether economic shocks - such as those caused by climate-related damages or by the modification of investment patterns for long-lived infrastructures to achieve mandatory decarbonization policies - will, or could, influence long-term growth pathways and generate a permanent and sizable loss of welfare. We venture to suggest that this novel approach leads to a modeling framework of considerable interest beyond its

\footnotetext{
* Corresponding author S. Hallegatte. CIRED, 45bis, Av. de la Belle Gabrielle, F-94736 Nogent-sur-Marne, France, Tel. 331439473 74. Fax. 33143947370.

Email address: hallegatte@centre-cired.fr (Stéphane Hallegatte).
} 
originally intended field of application. The initial results presented in this paper indicate that our framework helps to capture the role of institutional and technological inertia as key parameters that may control endogenous business cycles and even give rise to major changes in long-term growth trends.

The next section places our contribution in the context of existing modeling approaches to business cycles. Section 3 describes our non-equilibrium dynamic model NEDyM and the range of behavioral assumptions it can describe. Section 4 presents the basic behavior of NEDyM solutions for one of these options, namely the managerial economy with imperfect foresight; the equilibrium solution for this option is calibrated to roughly match the aggregate indicators of the European Union's economy for 2001, and the periodic solutions are compared to standard business-cycle descriptions. In Section 5 we investigate more generally how solution behavior changes as the model's key parameter, which governs investment dynamics, changes. These results are interpreted in terms of a systematic bifurcation analysis that leads from equilibrium to cyclic and on to chaotic behavior. In the last section we draw tentative conclusions and provide suggestions for future research.

\section{The role of inertia in endogenous business cycles}

The fact that major economic indicators - like production, prices, wages and consumption - undergo more-or-less regular ups and downs remains a major challenge for economic theory. One of the main trains of thought (e.g., Slutsky, 1927; Frisch, 1933; Lucas, 1975; Kydland and Prescott, 1982; King and Watson, 1996; Wang and Wen, 2004), is that the economic system has a single stable equilibrium and cycles result from random shocks on money supply, technology or productivity; these shocks are progressively absorbed by the economic system, which returns to its long-term equilibrium.

Another strand of literature, stemming from Keynes and Kalecki, uses nonlinear deterministic relationships between economic aggregates: starting from the Harrod (1939) model, which shows that growth becomes unstable if an investment accelerator is introduced, Samuelson (1939) demonstrated that this instability can be responsible for business cycles, while Kalecki (1937) obtained cyclical dynamics by introducing a delayed dependence of investments on past profits into a multiplier framework. Solow (1956) contested the "knife-edged" equilibrium path of Harrod, where a small sidestep could lead to disaster. His argument relied on allowing substitution between capital and labor to restore the possibility of equilibrium growth pathways. Nikaido (1996), however, showed that such substitution ensured the existence but not the stability of the steady-state growth, and that either instantaneous goods market clearing

— like in the Solow model — or a well-behaved investment response to goods 
market disequilibrium was necessary to guarantee stability, too.

Arrow (1989) and others emphasized, however, the lack of evidence for the existence of such a stable equilibrium. In his Nobel Prize lecture, Solow (1988) stressed that, after a perturbation "the economy that once strays from equilibrium growth [may] not automatically find its way back to any equilibrium path". His diagnosis was that "Growth theory was invented to provide a systematic way to talk about and compare equilibrium paths for the economy. In that task it succeeded relatively well. In doing so, however, it failed to come to grips adequately with the right way to deal with deviations from equilibrium growth".

Confrontations and hybridizations between balanced-growth theories and business-cycle theories lead to many ways of obtaining endogenous economic cycles: financial constraints and changes in income (Kaldor, 1940; Hicks, 1950); discontinuous shifts in investment in response to differences between a desired and real level of capital stock (Goodwin, 1951); changes in income distribution and the role of the destruction of the reserve army of labor in a Volterra-type predator-and-prey model (Goodwin, 1967); and various Keynesian feedback channels (Chiarella and Flaschel, 2000; Asada et al., 2004; Chiarella et al., 2005). In neoclassical optimal growth models, perfect market clearing and perfect foresight rule out demand and income distribution effects. Still, even in such models, endogenous cycles can arise from savings behavior (Day, 1982) and from interactions between overlapping generations (Reichlin, 1986); distinction between economic sectors (Benhabib and Nishimura, 1979) or between wealth effects and real-interest-rate movements (Grandmont, 1985). In some of these models, either Keynesian or neoclassical, business cycles can even lead to chaotic behavior (e.g., Day and Shafer, 1985; Chiarella, 1988); Rosser (1999) provides a review of the applications of chaos and complexity theory to economics.

Our contribution to these diverse attempts to model endogenous cycles and growth patterns arises from our focus on the inertia of economic systems. These inertial effects allow one to capture in a very compact way the frictional delays of the social machinery in which Solow saw one major reason for disequilibrium growth ${ }^{1}$. Into this category fall the constraints on equipment turnover, especially in the infrastructure sector; the progressive deployment of innovations; and all the social constraints that delay the immediate implementation of investment or consumer decisions.

An additional interest of our approach is that it allows, as we shall see, the

$\overline{1}$ "The markets for goods and labor look to me like imperfect pieces of social machinery with important institutional peculiarities. They do not seem to behave at all like transparent and frictionless mechanisms for converting the consumption and leisure desires of households into production and employment" (Solow, 1988, p.311). 
development of a modeling framework capable of representing various views of long-term economic growth. In particular, balanced-growth pathways can be reproduced, for some values of the model parameters, because we preserve Solow's view that capital and labor can be substituted for each other in the macroeconomic production function, therefore avoiding a systematic Harrod's knife-edged behavior. Transient behavior and endogenous business cycle can arise, on the other hand, since we add to Solow's framework the following two inertia-related effects:

(1) Delays in the mutual adjustments between production and demand or capital and labor; these delays may be due to regulation, but also to the inertia of institutional and technical systems including the deployment of research and development results.

(2) A Kalecki-type model of investment decisions that links investment decisions with profits, unlike in accelerator models (e.g., Goodwin, 1951; Nikaido, 1996), and allows one to represent possible suboptimalities in the decision process, due to possible gaps between short-term signals and long-term economic circumstances.

\section{A non-equilibrium dynamic model (NEDyM)}

NEDyM is a highly idealized macro-economic model that follows the classical Solow growth model in considering an economy with one representative producer, one representative consumer and one good, used both for consumption and investment.

The original Solow (1956) model is composed of a static core describing the market equilibrium, and a dynamic relationship describing the productive capital evolution. In NEDyM, we translate the static core into dynamic laws of evolution by building delays into the pathways toward equilibrium. This device introduces short-term dynamics into the model.

\subsection{Variables and parameters}

The 8 state variables, whose evolution is described by ordinary differential equations (ODEs), are listed in Table 1. The 11 other variables, which are connected to the 8 state variables by algebraic equations, are listed in Table 2 . In the climatological (Ghil and Childress, 1987) and meteorological (Kalnay, 2003) literature, it is common to call the first type of variables prognostic and the second diagnostic. The model parameters are listed in Table 3 and their values are justified in Section 4.1, where model calibration is discussed. 


\begin{tabular}{ccc} 
Symbol & Description & Unit \\
\hline$F$ & liquid assets of banks and companies & monetary \\
$H$ & goods inventory & physical \\
$K$ & capital & physical \\
$L$ & number of employed workers & millions of workers \\
$M$ & consumer nominal money stock & monetary \\
$p$ & price & monetary \\
$w$ & wages & monetary \\
$\Gamma_{i n v}$ & producer investment ratio & no unit \\
\hline
\end{tabular}

Table 1

List of the model state variables (prognostic variables).

\begin{tabular}{ccc} 
Symbol & Description & Unit \\
\hline$C$ & consumer consumption & physical \\
$D$ & total demand (=sales) & physical \\
Div & dividends & monetary \\
$\widetilde{D i v}$ & expected future dividends & monetary \\
$I$ & investment & physical \\
$L_{d}$ & optimal labor demand & number of workers \\
$L_{e}$ & effective labor demand & number of workers \\
$S$ & available savings & monetary \\
$Y$ & production & physical \\
$\Pi$ & gross profits & monetary \\
$\Pi_{n}$ & net profits & monetary \\
$\widetilde{\Pi}_{n}$ & expected future net profits & monetary \\
\hline & &
\end{tabular}

Table 2

List of the other model variables (diagnostic variables).

\subsection{Equations}

This section describes how equilibrium constraints between variables are transformed into dynamic relations, thus increasing the number of prognostic variables of our model. 


\begin{tabular}{ccc} 
Symbol & Description & Value \\
\hline$A$ & total productivity & $A=9.3 \times 10^{-2}$ \\
$e_{\text {full }}$ & equilibrium rate of employment & $e_{\text {full }}=90 \%$ \\
$L_{\text {max }}$ & total number of workers & $L_{\text {max }}=180$ million \\
$\gamma_{\text {save }}$ & consumer savings ratio & $\gamma_{\text {save }}=0.3$ \\
$\nu$ & financial standard of profitability & $\nu=3 \% \cdot \mathrm{yr}^{-1}$ \\
$\rho$ & required return on equity & $\rho=10 \% \cdot \mathrm{yr}^{-1}$ \\
$\tau_{\text {dep }}$ & capital depreciation characteristic time & $\tau_{\text {dep }}=20 \mathrm{years}^{-1}$ \\
\hline$\alpha_{\text {inv }}$ & producer investment coefficient & varying \\
$\alpha_{F}$ & using rate of the producer liquid assets & $\alpha_{F}=0.2 \mathrm{yr}^{-1}$ \\
$\alpha_{M}$ & using rate of the consumer money stock & $\alpha_{M}=0.2 \mathrm{yr}^{-1}$ \\
$\alpha_{p}$ & price coefficient & $\alpha_{p}=3.610^{-3}$ \\
$\tau_{\text {empl }}$ & employment characteristic time & $\tau_{\text {empl }}=2 \mathrm{years}$ \\
$\tau_{\text {wage }}$ & wage characteristic time & $\tau_{w a g e}=2 \mathrm{years}$ \\
\hline
\end{tabular}

Table 3

List of the model parameter values. The first 7 parameters determine the equilibrium of the model and are calibrated; the last 6 do not influence this equilibrium, only the model dynamics. The standard values of the latter, as used in Section 4, are shown in this table and are chosen in an ad hoc manner; $\alpha_{i n v}$ will be varied systematically in Section 5.

\subsubsection{Goods market}

In the Solow model, the price $p$ is determined by the equality of production $Y$ and demand $D, Y=D$. In NEDyM, $Y \neq D$ and a goods inventory $H$ is introduced, filled by $Y$ and emptied by $D$. At any time $t, Y$ can differ from $D$ : temporary overproduction or underproduction is possible. The dynamics of the goods inventory is driven by the difference between production and demand. It can be either positive or negative. It should be interpreted as a selling lag (or the opposite of a delivery lag): a positive value refers to temporary overproduction and can be interpreted as the time necessary to a producer to sell the goods he has produced. A negative value refers to underproduction and can be interpreted as the time it takes a consumer to get the goods he has ordered. Underproduction can come from the technical lag to produce, transport and distribute goods and from possible undercapacity due to the inertia to build up new capacity.

Price increases or decreases as a function of the goods inventory situation, tending to return the state of the model to the equilibrium $Y=D$ with a null goods inventory $(H=0)$. This relaxation toward equilibrium guarantees the 
long-term "conservation of mass" in the model: any good that is produced is eventually sold, any good that is bought is eventually produced. As a consequence, the equality of production and demand is verified over the long term, but the delays in price adjustment can break this equality in the short term.

- Demand $D$ equals the sum of consumption $C$ and investment $I$ :

$$
D=C+I .
$$

This is what we call a diagnostic, or algebraic, relation in our model.

- Goods inventory changes are driven by the difference between production and demand:

$$
\frac{d H}{d t}=Y-D
$$

We call this a prognostic, or differential, relation.

- Price evolution:

$$
\frac{d p}{d t}=-p \cdot \alpha_{p} \cdot \frac{H}{D} .
$$

Price changes are driven by the goods inventory state, with a given characteristic time allowing to account for an inertia in the price adjustment ${ }^{2}$. If the inventory is positive, it means that the production is not sold (or is sold after a delay), and that the market power is on the side of the buyers who can make the price decrease. If the inventory is negative, goods have to be produced and the price will increase. The inventory is compared with the demand to determine the price variation. Note that a possible asymmetry in the price behavior could be implemented at a later stage.

\subsubsection{Production function}

As in the Solow (1956) model, we use a Cobb-Douglas function (Cobb and Douglas, 1928):

$$
Y=f(L, K)=A \cdot L^{\lambda} \cdot K^{1-\lambda},
$$

where $\lambda=2 / 3$ and $A$ is the total factor productivity. The algebraic relation (4) gives the production as a function of the productive capital $K$ and the number

$\overline{2}$ This price evolution rule differs slightly from the model of Calvo (1983) and of King and Watson (1996), who introduce inertia through a static, monopolistic competition model and a "target" price calculated by a fixed markup over the marginal cost. Here we aim to represent the adjustment process of the price in response to changes in production or demand. Our formula (3) is very close, however, to the classical "law of supply and demand" (e.g., Nikaido, 1996), in which price adjusts according to the difference between supply and demand. The only modification is that the price adjusts according to the goods inventory, which integrates the difference between supply and demand over time. 
of employed workers $L$. The value of $\lambda$ is chosen so that, at equilibrium, the distribution between labor income and capital income is close to the one currently observed. Note that the productive capital is considered as a set of physical objects (machines, plants, infrastructures...) and not only as a sum of monetary investments.

This production function calls for two remarks. First, the Cobb-Douglas production function was proposed for long-term growth models, since it allows for perfect substitution between capital and labor, and its application to shortterm models may not be entirely appropriate (see Chiarella et al., 2005, Section 3.1). Second, using this function amounts to assuming that the producer does not reduce production when demand is lower than production capacity. The producer thus assumes that production will, in all cases, eventually be sold at the current price and can be stocked at no cost. Since, in the real world, stocking is costly and future sales are uncertain, production is often lower than capacity and our assumption is only a rough approximation. These two unrealistic features will be corrected in a follow-up version of the model, but they do not prevent the present version from providing interesting results, as we shall see.

\subsubsection{Labor market}

In the Solow model, $w$ is such that $L=e_{\text {full }} \cdot L_{\text {max }}$ : the economy is always at full employment. NEDyM models instead the producer as setting an effective labor demand $L_{e}$ that would maximize his/her profits, as a function of the price and the wages; the latter are flexible over the long term and rigid over the short term. The number of employed workers $L$ is driven by this effective labor demand with a delay. If labor demand is higher (respectively lower) than the equilibrium level $e_{f u l l} \cdot L_{\max }$, the wage increases (respectively decreases), so as to drive the employment level back to its equilibrium value.

- Employment rate evolution:

$$
\frac{d L}{d t}=\frac{-1}{\tau_{e m p l}}\left(L-L_{e}\right) .
$$

The producer adjusts the number $L$ of workers in order to attain his effective labor demand $L_{e}$. Technical constraints, however, prevent an instantaneous adjustment process: changing the labor/capital ratio requires the producer to adapt the working organization and, possibly, even the productive capital has to be changed. Additionally, worker protection laws, administrative tasks, transaction costs and the search for qualified workers are also involved in the adjustment process. This is taken into account through the parameter $\tau_{e m p l}$, which is the characteristic time of the convergence of $L$ toward $L_{e}$. 
- The evolution of nominal wages follows a Phillips (1958) curve:

$$
\frac{d w}{d t}=\frac{w}{\tau_{\text {wage }}}\left(\frac{L}{L_{\max }}-e_{\text {full }}\right) .
$$

Following Rose (1967), wages are solely determined by the employment rate, with a given characteristic time. Calibrating $\tau_{\text {wage }}$ allows NEDyM to account for rigidities in the labor market. Wages increase when the employment rate is high, because of the corresponding negotiating power of the workers, individually or through trade unions.

At this stage no prevailing inflation climate nor price inflation expectations are taken into account, in spite of their potential importance (e.g., Chiarella et al., 2005). Additional factors that may affect the differential relation (6) need eventually to be discussed because the social organization, the institutional conditions, worker protection laws and agreements between social groups all play an important role in determining wages.

- Producer labor demand optimization: The producer aims at optimizing his labor demand $L_{d}$, assuming that his production will be sold and equating the labor marginal productivity to the real wage. This optimization is modeled by the diagnostic relation:

$$
\frac{w}{p}=\frac{d f}{d L}\left(L_{d}, K\right)
$$

Here again, the producer assumes, somewhat unrealistically, that the entire production will eventually be sold at the current price and can be stocked at no cost.

- Effective employment demand:

$$
L_{e}=\operatorname{Min}\left(L_{\max }, L_{d}\right)
$$

\subsubsection{Consumer behavior}

In the Solow model, total income from wages and profits, i.e. $(w L+\Pi)$, is always equal to consumption plus savings, i.e. $(p C+S)$. In NEDyM, the consumer has an income of $(w L+D i v)$, wages plus dividends, and can consume $C$; in addition he can save, either by stocking (in his stock of money $M$ ) or by making this savings available for investment $(S)$ through the purchase of new equity (savings $S$ in NEDyM, therefore, are not directly comparable with the Solow model's savings; for more details, see below the Producer behavior section).

- Consumer stock of money:

$$
\frac{d M}{d t}=(w \cdot L+D i v)-(p \cdot C+S)
$$


This prognostic rule for stock evolution introduces a delay in consumer behavior: an increase in his income will increase progressively consumption and available savings.

- Consumer consumption :

$$
C=\left(1-\gamma_{\text {save }}\right) \cdot \frac{1}{p} \cdot \alpha_{M} \cdot M
$$

At each instant, the sum of consumption and available savings is equal to a constant part of the consumer stock of money, $\alpha_{M} M$. This relation introduces a delay in the behavior of the consumer with respect to the change in his income. Moreover, it means that, when his income increases, his equilibrium stock of money increases also, so as to take into account the need for an increased stock of money to buy more goods. As in the Solow (1956) model, the distribution between available savings $S$ and consumption $C$ is fixed exogenously by $\gamma_{\text {save }}{ }^{3}$. Additional spill-over effects could be modelled here like, for instance, the relationship between unemployment and saving ratio through precautionary saving.

- Consumer savings:

$$
S=\gamma_{\text {save }} \cdot \alpha_{M} \cdot M
$$

Consumer consumption and savings are therewith both modeled in NEDyM by diagnostic relations. Physical investment and consumption are measured in physical units, since they represent bought goods, while available savings is measured in monetary units. The redistributed dividends Div will be modeled in connection with producer behavior.

\subsubsection{Productive capital}

The productive capital $K$ evolves here prognostically, as in the classical Solow (1956) model:

$$
\frac{d K}{d t}=\frac{-1}{\tau_{d e p}} K+I
$$

\subsubsection{Producer behavior}

In the Solow model, sales $p D$ equal wages $w L$ plus profits $\Pi$, and investment $I$ equals savings $S$. A key feature of NEDyM is its introduction of an investment module, inspired by the Kalecki (1937) models, which forces one to make explicit the assumptions about investment behavior and to account for possible

3 The consumer savings ratio $\gamma_{\text {save }}$ is applied here to the consumer stock of money, not to the consumer income, and is thus not directly comparable with the classically defined savings ratio (e.g., Solow, 1956). 
alternative regimes, a question which does not arise in the Solowian models. We introduce a stock of liquid assets $F$ of companies, which is modeled prognostically; here $F$ includes both the producer's stock of money and that of financial intermediaries like banks.

The stock $F$ is filled by gross profits $\Pi$ and by the available savings $S$ from consumers. We assume that the consumers' savings $S$ are made available to companies by sales of new equity, directly or through financial intermediaries. Assuming that the Modigliani-Miller theorem's hypotheses are verified (Modigliani and Miller, 1958), adding debts and loans does not change the investment problem.

At each time, a fixed part $\alpha_{F} F$ of $F$ is used for physical investment and for distributing dividends. An investment ratio $\Gamma_{i n v}$ is used to distribute $\alpha_{F} F$ between physical investment $I$ and dividends Div.

Dividends Div are that part of the company's liquid assets that is redistributed to the consumers, but one key feature of NEDyM is that these dividends represent more than redistributed dividends per se: they include redistributed dividends, but also sales of assets, capital gains, spin-offs to shareholders and repurchase of shares. The equivalence between all these categories is comprehensively demonstrated by Copeland and Weston (2003). This modeling of capital gains, which makes Div be different from the Solow model's profits, is justified by the fact that, when the financial investment is higher than the physical investment, the additional part goes back to the shareholders, either as an increase in dividends or as a consequence of a spin-off in shares.

We translate here the fact that if the producer does not want to invest, he/she does not emit new shares and the savings that a consumer uses to buy shares $(S)$ are only transferred to other consumers, i.e. to himself through Div in the model. This possibility is responsible for a non-productive closed loop of money, from the consumer stock of money, through savings to the producer stock of money, and back to the consumer stock of money through dividends. This closed loop can be interpreted as the process that changes, at equilibrium, the unrelated ex ante savings and investment into consistent ex post variables. Whatever the amount of available savings, if the economic situation is such that the capital profitability is low, these savings will not be transformed into physical investments but be redistributed through Div. Thus, the equality between savings and investment does not hold: savings and investment decisions are independent, at least to some extent. This loop has a very short characteristic time, of a few weeks, which explains the shortness of the model timestep (see below).

NEDyM assumes that physical investment $I$ is driven, via $\Gamma_{i n v}$, by the capital profitability, with an inertia that represents: (i) the fact that producers want 
to avoid uncertainties and adjustment costs (Day, 1979; Lucas, 1967) and thus do not react instantaneously to price signals; and (ii) the delay between the time an investment is decided upon and the time it is realized (Kalecki, 1937).

- Changes in the producer stock of liquid assets $F$ are thus given by the differential relation:

$$
\frac{d F}{d t}=\Pi+S-D i v-p I
$$

- Gross profits $\Pi$ are given by sales $p D$ minus labor costs $w L$ :

$$
\Pi=p D-w L .
$$

- Dividends and physical investment distribution follow the diagnostic relation:

$$
p I+D i v=\alpha_{F} F .
$$

The producer uses a fixed amount of his stock of liquid assets for physical investment and dividends. The distribution between physical investment and dividends depends on the investment ratio $\Gamma_{i n v}$ :

$$
I=\Gamma_{i n v} \cdot \frac{1}{p} \cdot \alpha_{F} F
$$

- Producer investment ratio:

We model investment as a function of profitability (Kalecki, 1937; Rose, 1967; Malinvaud, 1982), and not as a function of the aggregated demand level, as in investment accelerator models (e.g., Harrod, 1939; Goodwin, 1951; Schinasi, 1981; Nikaido, 1996). This modeling choice allows us to examine the consequences of a large range of decision-making behavior. This range can be described in a plane spanned by two axes.

The first axis marks the possible weights given to the two opposite views on agents' expectations, myopic and rational. Covering this wide range of options would have blurred our intended analysis of the endogenous mechanisms behind economic cycles, and so we retained, at this stage, the hypothesis that agents form their expectations based on observed values, either because they are myopic or because uncertainty makes current values be the best proxy for future values.

The second axis marks the possible weights given to the two opposite views on who are the decision makers in companies. At one end of the scale is the Berle-Means firm (Berle and Means, 1932; Roe, 1994), in which powerful managers aim at maximizing the long-term growth. In this case, the producer redistributes as dividends only the amount that is still available after the profitable investments have be funded. At the other end are the shareholder-driven firm, in which shareholders are able to force the management to invest only what is left after the distribution of dividends, which have to yield a given level of return on equity. This behavior derives from one 
of the trends in economic organization since the mid-1980s, with company control edging more and more towards the shareholders, through institutional investors (e.g., Jensen, 1986).

This second axis is critical for discussing institutional issues related to long-lived investments, and so we have followed the distinction proposed by Aglietta and Rebérioux (2004) between a managerial economy and a shareholder economy. This distinction is obviously a caricature of opposite views of the economic system, both in actual terms (how does the system really function?) and in normative terms (what is an optimal balance between the power of the managers and of the shareholders?). But it has the advantage of being easy to translate into modeling terms that are clear enough to help determine how assumptions about decision-making behavior and institutional organization may impact economic cycles.

We now describe how each of these two options is represented in our modeling framework:

(1) Managerial economy:

The producer's net profit $\Pi_{n}$ follows the accounting definition of profit (Copeland and Weston, 2003), i.e. gross profits minus capital depreciation:

$$
\Pi_{n}=\Pi-\frac{1}{\tau_{d e p}} p K=p D-w L-\frac{1}{\tau_{d e p}} p K,
$$

and the investment ratio follows the prognostic rule:

$$
\frac{d \Gamma_{i n v}}{d t}=\left\{\begin{array}{ll}
\alpha_{i n v}\left(\gamma_{m a x}-\Gamma_{i n v}\right)\left(\frac{\widetilde{\Pi}_{n}}{p K}-\nu\right) & \text { if } \frac{\widetilde{\Pi}_{n}}{p K}-\nu>0 \\
\alpha_{i n v}\left(\Gamma_{i n v}-\gamma_{m i n}\right)\left(\frac{\widetilde{\Pi}_{n}}{p K}-\nu\right) & \text { if } \frac{\widetilde{\Pi}_{n}}{p K}-\nu \leq 0
\end{array} .\right.
$$

The distribution between dividends and investment depends on the expected net profits per capital unit $\widetilde{\Pi}_{n}$, compared with a standard of profitability $\nu$. If the expected net profit per capital unit $\widetilde{\Pi}_{n} /(p K)$ is higher than this standard, the producer increases his physical investments; if, on the contrary, the expected profit is lower than $\nu$, investments are reduced. Assuming that observed values are the best guess of expected values at each point in time leads to:

$$
\widetilde{\Pi}_{n}=\Pi_{n}
$$

The extrema $\gamma_{\min }=0$ and $\gamma_{\max }=0.8$ of $\Gamma_{i n v}$ are parameters that represent, respectively, the positivity of investment and the cash-flow constraint. Their values are arbitrary, to some extent, in the sense that somewhat different values would be compatible with an acceptable calibration of the model; but we checked, through sensitivity tests, that a reasonable range of $\gamma_{\text {min }}$ and $\gamma_{\text {max }}$ does not change qualitatively the model's behavior. Note that rule (18) behaves asymmetrically: for instance, the investment ratio $\Gamma_{i n v}$ can decrease more rapidly in response to a negative profitability signal when investment is high, because the factor $\left(\Gamma_{i n v}-\gamma_{\min }\right)$ is large. On 
the contrary, the decrease is slowed down (respectively cancelled) when investment is already low (respectively null), because the factor $\left(\Gamma_{i n v}-\gamma_{\min }\right)$ is close (respectively equal) to zero in this case.

The prognostic rule (18) can be interpreted using Tobin's (1969) Q: if the future net profit is assumed equal to the current one and if the company value $V$ is equal to the discounted net profit flux, then $V=\Pi_{n} / \nu$, where $\nu$ here is the discount rate; $Q$ is then defined as the company value divided by its capital replacement value $p K$. In this approach, $Q$ drives the investment in the sense that investment progressively increases when $Q>1$ and decreases when $Q<1$.

The choice of $\nu$ determines the level of investment and thus the future production levels. In this article, $\nu$ is assumed to be constant at $3 \%$. This value of $\nu$ is smaller than the currently observed financial standard of profitability, because the model does not separate between privatesector investments, decided solely on the basis of financial profitability, and public-sector ones, which take additional considerations into account and have therefore, in general, lower internal return rates. Investment rule (18) is consistent with the functioning of the American economy before the 1980s, as described by Berle and Means (1932) and Roe (1994).

(2) Shareholder economy:

In this case, the investment rule becomes

$$
\frac{d \Gamma_{i n v}}{d t}=\left\{\begin{array}{ll}
\alpha_{i n v}\left(\gamma_{\max }-\Gamma_{i n v}\right) \cdot\left(\frac{\widetilde{D i v}+E r r}{p K}-\rho\right) & \text { if } \frac{\widetilde{D i v}+E r r}{p K}-\rho>0 \\
\alpha_{i n v}\left(\Gamma_{i n v}-\gamma_{\min }\right) \cdot\left(\frac{\widetilde{D i v}+E r r}{p K}-\rho\right) & \text { if } \frac{\widetilde{D i v}+E r r}{p K}-\rho \leq 0
\end{array} .\right.
$$

The allocation between dividends and investment depends here on the expected dividends per capital unit $\widetilde{D i v}$. In this regime, if the expected dividends per capital unit are higher than the required return on equity $\rho$, the producer increases investments; in the opposite case, investments are reduced to the level that allows the redistribution of the required amount of dividends. Again, expected dividends are supposed to be equal to observed dividends:

$$
\widetilde{D i v}=\operatorname{Div}
$$

To capture the difference between an economy subject to shareholder control and the previous managerial organization, it is, however, not sufficient to replace $\nu$ by $\rho$ and $\widetilde{\Pi}_{n}$ by $\widetilde{D i v}$. In fact, as already mentioned, the value of Div includes all investor gains, including capital gains and losses. This is why the variable Err has to be introduced to represent how unexpected variations in profits affect the equity value of companies. The variable Err translates the variations of equity values due to incomplete information in capital markets or formation of speculative bubbles. Assuming that Err is null amounts to assuming a "utopian shareholder economy," in which markets operate so perfectly that shareholders fully 
incorporate all information in their evaluation of the expected value of an asset. This assumption is, obviously, at variance with the facts. Thus, for instance, during the 2001 crisis, a strong decrease in asset prices, which could be represented here by a strong decrease in Err, was in part compensated by higher dividends.

For the same reason that we did not explore here the whole range of decision behavior in a managerial economy, we will not elaborate in this paper on the consequences of various types of shareholder behavior. Preliminary results for a "utopian shareholder economy" show behavior that is less cyclic than in Sections 4.2 and 5 here, while the opposite result can be achieved in a shareholder economy with non-negligible values of Err.

A systematic comparison of how shareholder and managerial economies function, with respect to their business cycles and other characteristics, is a fundamental goal of our approach. This goal, however, cannot be achieved without a prior understanding of the mechanisms behind endogenous cycles. We focus therefore in the rest of this paper on the analysis of the managerial economy, leaving the analysis of the shareholder version for a subsequent paper.

\section{Model calibration and basic results}

The model described in detail in Section 3 can be summarized in the equation

$$
\frac{d \mathbf{X}}{d t}=N(\mathbf{X})
$$

where the vector $\mathbf{X}$ has as its components the 8 prognostic state variables listed in Table 1. Adding up Eqs. (9) and (13) shows that our NEDyM model obeys a conservation law for the amount of money, $M+F=$ const., since $D=C+I$. We verified, in fact, that the numerical simulations we carry out satisfy this conservation law, without having to impose it explicitly in the model ${ }^{4}$. This verification provides an independent check on the accuracy of our solutions. The presence of such a conservation law implies that NEDyM has either zero or an infinite number of equilibria. Using the additional constraint of a price $p=1$, however, it can be easily proven, by solving the algebraic, steady-state equation $N(\mathbf{X})=0$, that the model has a unique equilibrium.

$\overline{4}$ In fact, the sum $M+F$ is constant to within a tolerance of $10^{-6}$ in the double-digit calculations of the numerical solutions, and there is no systematic drift. 


\subsection{Model equilibrium}

When there is no investment dynamics, i.e. when $\alpha_{i n v}=0$ in Eq. (18) or (20), this unique equilibrium $\mathbf{X}=\mathbf{X}_{0}$ is stable, whatever type of economy we consider, managerial or shareholder-driven. This stability of the equilibrium is still observed for sufficiently small values of $\alpha_{i n v}\left(e . g . \alpha_{i n v}=1.0\right)$.

The price of the goods being arbitrarily set at 1 , six model parameters $(A$, $e_{\text {full }}, L_{\text {max }}, \gamma_{\text {save }}, \nu$ and $\tau_{\text {dep }}$; see Table 3 ) are chosen such that this equilibrium state is consistent with observable variables for the 2001 economic state of the 15-country European Union: production, consumption, investment, savings, employment, wages, and capital income ${ }^{5}$.

The dynamic parameters $\left(\alpha_{i n v}, \alpha_{F}, \alpha_{M}, \alpha_{p}, \tau_{e m p l}, \tau_{\text {wage }}\right)$ are not calibrated separately on historical data for several reasons: (i) because many variables are not directly observable at all (e.g. $K, F$, or $M$ ); (ii) because the model has a very short time step, and very few data are available on such a time scale; and, most importantly, (iii) because we do not pretend to reproduce historical data with such a simple, idealized model. We only try to reproduce the business cycle stylized facts — such as its asymmetric shape and characteristic lags between main economic variables - and to identify the driving mechanisms. Our NEDyM model is built to capture interactions between short-term and long-term economic behavior. Hence, reproducing the qualitative features of the cycle is more valuable at this point than reproducing historical data through an econometric calibration, which is only valid, in any case, over the short term.

Reasonable values are thus chosen in an ad hoc manner for five of the dynamic parameters, while the effect of $\alpha_{i n v}$ on model behavior will be systematically studied in Section 5. In future work with more detailed versions of NEDyM, we expect to use the ideas of parameter estimation from the engineering and control literature (Gelb, 1974; Kendrick, 2005) in order to determine the history of the system, as well as the dynamic parameter values, from the observable economic variables, when and where available. Such ideas have been successfully applied for very large systems with partial and irregular observations, in meteorology (Kalnay, 2003) and oceanography (Malanotte-Rizzoli, 1996; Ghil, 1997).

5 We do not calibrate, however, either the investment ratio and the stock of productive capital, nor the values of the consumer stock of money and the producer stock of liquid assets: measuring investment ratio and productive capital involves difficult theoretical problems and the availability of credit in the real economy makes the model's stocks of money and liquidities difficult to compare with actual stock of money. 
All parameter values used in this section are listed in Table 3. The corresponding equilibrium state is reproduced in Table 4, where it is compared with observed values for the European economy from Eurostat (2002).

We note that out of the available amount of money of 6 trillion euros (available savings $S$ plus gross profits $\Pi$ ), 2 trillion are used for physical investment $I$ and 4 trillion are redistributed as dividends Div (in the broad sense, i.e. including dividends, spin-off to shareholders, etc.). Moreover, total income (wages $w L$ plus dividends Div) is 10 trillion euros, greater than GDP (9 trillion euros). This is explained by the fact that we do not consider net flows over one year (as the national accounting system does) but oriented flows (summed over one year). In NEDyM, as explained in section 3.2.6, there is a nonproductive closed loop from the consumer stock of money, through consumer savings, on to dividends and back to the consumer stock of money. This loop is not captured in the national accounting. If we calculated instead net flows that are comparable with the national accounting system, dividends (ex ante value) in the model are reduced to 3 trillion euros (ex post value) and consumer savings (ex ante value) are reduced to 2 trillion euros (ex post value), leading to a consistent equilibrium.

With the parameter set given in Table 3, the equilibrium values of the NEDyM variables, calculated by solving $N(\mathbf{X})=0$, correspond to the steady state of a neo-classical Solow model with an equivalent savings ratio $\gamma_{\text {save }}^{*}=22 \%$.

\subsection{Basic model oscillations}

In the previous subsection, we have seen that our NEDyM model exhibits, for reasonable parameter values, an equilibrium solution that resembles, in many respects, a fairly realistic, neo-classical equilibrium state. The true interest of NEDyM, though, lies in its time-dependent behavior, which we start to explore in the present subsection. For the parameter values in Table 3, and with $\alpha_{i n v}=2.5$, the unique equilibrium solution $\mathbf{X}_{0}$ of Table 4 is unstable, but our model possesses a stable periodic solution, with variables that oscillate around the equilibrium values at the equilibrium $\mathbf{X}_{0}$. This periodic solution is shown in Fig. 1.

The model oscillations in economic aggregates - profits, production and employment - exhibit several characteristics of the business cycles of the second part of the $20^{\text {th }}$ century. The amplitude of the oscillation is unrealistic but its 5.4-year period is consistent with the mean business cycle period (see Zarnovitz, 1985; King and Watson, 1996; Kontolemis, 1997; Süssmuth, 2002, and the National Bureau of Economic Research (NBER) website ${ }^{6}$ ). The ob-

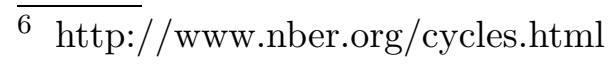




\begin{tabular}{cccc} 
Symbol & Description & (and net flows) & observed values \\
\hline$Y$ & production (=demand=GDP) & 9 & 8.8 \\
$L$ & number of employed workers (millions) & 162 & 167 \\
& (in percent) & $(90 \%)$ & $(92.6 \%)$ \\
$w L$ & total annual wages & 6 & 5.6 \\
$C$ & consumer consumption & 7 & 6.8 \\
$S$ & consumer available savings & $3(2)$ & 1.8 \\
$\Pi I$ & gross profits & 3 & 3.2 \\
$D i v$ & annual dividends & $4(3)$ & 3.2 \\
$I$ & physical investment & 2 & 1.8 \\
\hline$\gamma_{i n v}$ & producer investment ratio & 0.31 & \\
$K$ & productive capital & 39 & \\
$M$ & consumer stock of money & 53 & \\
$F$ & producer stock of liquid assets & 32 & \\
$H$ & goods inventory & 0 &
\end{tabular}

Table 4

NEDyM equilibrium state (when necessary the corresponding net flows comparable with the national accounting system are in parentheses) and EU-15 economic variables in 2001 according to Eurostat (2002). Every value except employment is in trillions of euros. This equilibrium is independent of the value of $\alpha_{i n v}$, but can be either stable or unstable depending on this parameter (see text). The equilibrium provided here is for a price $p=1$. With the same set of parameters, there is a different equilibrium for each value of the price, since money is neutral in our model at equilibrium.

served variability in the period, however, is not reproduced in Fig. 1, since NEDyM produces only regular cycles for $\alpha_{i n v}=2.5$; see, however, the results for higher values of $\alpha_{i n v}$ in Section 5 .

The model cycle is composed of several phases, which are consistent with the cycle description in the review paper by Zarnovitz (1985), and whose durations are consistent with the data of Kontolemis (1997), Süssmuth (2002) and NBER.

From $t=0$ to $t=1$ years, a recovery phase, during which the production increases with slight oscillations. This recovery phase is characterized by an increasing employment level, accompanied by increases in consumption and investments. This is responsible for an increase in total demand, which leads to 

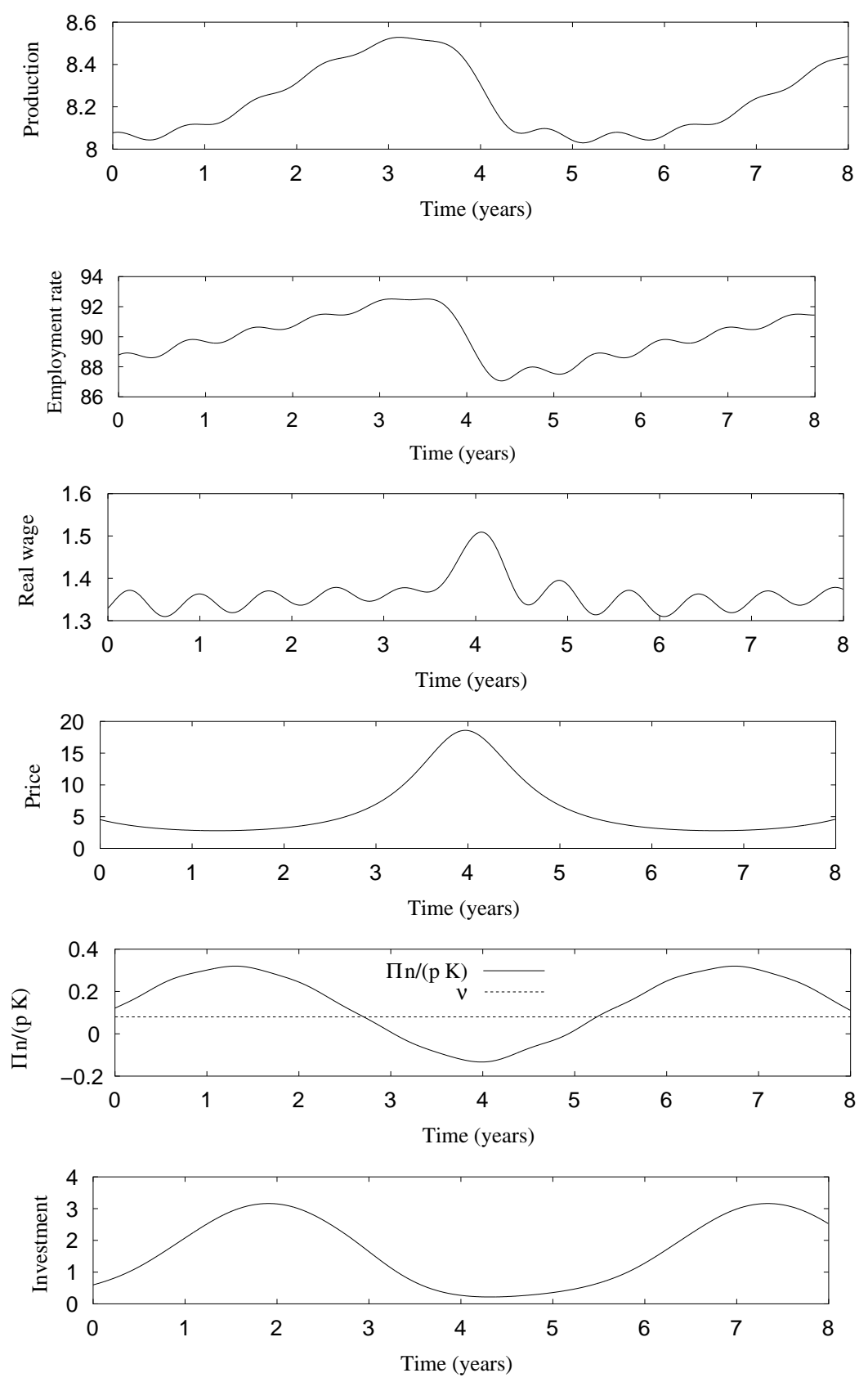

Fig. 1. Model business cycles for $\alpha_{i n v}=2.5$; for clarity, more than one full cycle is plotted. The variables represented are: (a) production $Y$; (b) employment rate; (c) real wage $w / p ;$ (d) price $p$; (e) the net profits per capital unit $\Pi_{n} /(p K)$, with the financial standard of profitability $\nu$ (dotted); and (f) investment $I$.

a rise in profits (and price) and consequently feeds back on investments (and employment level). These positive feedback loops constitute the multiplieraccelerator effect (Harrod, 1939), which is a short-term Keynesian effect.

From $t=1$ to 3 years, an expansion phase, during which the employment rate is high and increases further, while the real wages are rising; this lasting 
favorable development leads, however, to a growing inflation rate of price and wage that reduces the multiplier-accelerator effect on investment. A decrease in consumption is also observed because inflation reduces the purchasing power of the consumer stock of money, such as in Pigou's (1947) effect, but the income from sales $p D$ is approximately constant. During this phase, the net profits per capital unit, $\Pi_{n} /(p K)$, continuously decrease, because of the labor cost increases and because inflation increases the value of the capital $(p K)$.

This phase of growing investment and increase in the circulation velocity of money correspond: (i) to a period of Marxian "destruction of the reserve army of labor," which is also responsible for the profit decrease in Goodwin (1967), Skott (1989) or Rose (1967); and (ii) to an inflation period, during which the price increase reduces the net profits per capital unit ${ }^{7}$. This reduction in profits is a classical effect, due to the labor availability constraint and to the production system inertia; it opposes the investment instability and is responsible for the cycle's turning point.

From $t=3$ to 4.5 years, the contraction phase: at $t=3$ years, the net profit per capital unit $\Pi_{n} /(p K)$ falls below the financial standard $\nu$ and so the investment ratio begins to decrease, amplifying the demand decrease due to the inflation, and leading to a reduction in sales income $(p D)$. Profits are thus brutally reduced. The economy reaches a situation of over-production, the goods inventory increases quickly, which causes the price to stabilize and then decrease from $t=4$ years on. At that time, there is deflation: the price decreases and the employment rate decreases very quickly. The real wages increase during the boom and the early contraction, and begin to decrease during the late contraction and the depression. The profit per capital unit keeps decreasing during the early contraction and then begins to recover.

From $t=4.5$ years to $t=5.2$ years, the depression phase: the investment ratio keeps decreasing but, because of the price decrease, the consumption begins to increase again. Moreover, for reasons that are the symmetric opposite of those in the expansion phase, the real wage, employment and price decrease restore the net profits per capital unit, until $\Pi_{n} /(p K)$ rises again above the financial standard of profitability at $t=5.2$ years. At that point, the investment ratio rises again and the economy enters into a new recovery phase.

The NEDyM business cycle is thus consistent with the stylized facts explored by Zarnovitz (1985) (see in particular his Table 4). According to this author, the following relationships hold: the variables that are roughly coincident with the cycle are production $Y$, unemployment $\left(L_{\text {full }}-L\right) / L_{\text {full }}$; inflation $(d p / d t) / p$ and the circulation velocity of money. The variables that lead the

$\overline{7}$ The price increase makes the profits rise, but it downsizes also the demand and increases the productive capital value. The total effect is a downsizing of the profit per capital unit. 
cycle are the new orders for consumer goods and material, related here to consumption $C$; the change in unfilled orders, related here to the time derivative of the goods inventory $d H / d t$; the profit margins and the ratio of price to unit labor cost, related here to the gross profits $\Pi$. The variables that lag the cycle are the real wage $w / p$; labor share in national income $w L /(w L+D i v)$; and the inventories $H$.

These phase relationships are well reproduced by NEDyM, overall. Moreover, our model captures the co-movement of inflation and price with the cyclical component of production (e.g., King and Watson, 1996; Yun, 1996): inflation is procyclical and aggregate price countercyclical (but positively correlated with the lagged values of production), as observed in the data. This satisfying NEDyM behavior arises from nominal price rigidity ${ }^{8}$ and is consistent with the "new Keynesian Phillips curve"(Galí, 2000) that establishes a positive link between inflation and some measure of overall activity.

Notice also that our model reproduces the observed asymmetry of business cycles (see NBER website or Kontolemis, 1997), with the recession phase in terms of production and employment much shorter than the expansion phase. This asymmetry is not due to the asymmetry of Eq. (18), but to the following process: during the expansion phase, the economy shifts from overproduction to underproduction, and the goods inventory becomes negative, thus leading to price increases. The total demand is, however, high during this phase, and the amount of goods inventory stays moderate when compared with demand. As a consequence, the price responds only slowly. To the contrary, during the contraction phase, the total demand is very low. Thus, when the economy shifts back from underproduction to overproduction, the corresponding positive goods inventory becomes suddenly quite high, when compared with demand, and the price responds rapidly. This difference explains why the recession is more brutal than the recovery.

The main mismatches between our model cycle and the Zarnovitz (1985) stylized cycle are: (i) the fact that the total income $w L+D i v$ is lagging in the model, unlike in reality, where it is coincident. This is due to the fact that the NEDyM oscillation in total labor costs $w L$ has a much greater amplitude than the gross profits $\Pi$, which is unrealistic. (ii) The fact that the total sales decrease too early in the cycle and that the total sales oscillation is larger than the production oscillation. Both problems are linked to the amplitude of the price-and-wage oscillation being too large. We expect to obtain an even better agreement with stylized business cycles, as described in the literature, by combining a better calibration of our model, according to the parameter es-

\footnotetext{
8 Wang and Wen (2004) explain the same behavior by an endogenous monetary policy acting upon the illusion that prices are sticky in a flexible-price real-cycle model.
} 
timation ideas outlined in Section 4.1, with accounting for the direct influence of quantities on behaviors (see for instance, Chiarella et al., 2005).

All along our model cycle, a shorter-period oscillation in wages and employment is observed, which also affects production; see especially panels (a)-(c) of Fig. 1. The period of this oscillation is of slightly less than a year. Macroeconomic dynamics is affected by several seasonal forcing factors (e.g., agricultural production, consumption patterns, etc; see Wen (2002)), which are not present in the current version of NEDyM. In a more realistic model version, in which seasonal effects would be present, this subannual oscillation might be frequency-locked to the seasonal cycle, and thus amplify the annual oscillation (Winfree, 1980; Ghil and Childress, 1987; Jin et al., 1994, ,1996).

Notice that NEDyM is not Keynesian per se, since every behavioral relationship depends only on prices, even if the delays in price adjustment can be responsible for Keynesian behavior over the short term. In other words, prices and wages do not adjust instantaneously, but agent decisions (investment, labor demand, etc.) are still made as a function of these variables; there is no direct influence of quantities (e.g. goods inventory) on the decisions.

\section{Time-dependent model behavior}

It turns out that the behavior of such a simple dynamic model can be surprisingly rich. Rather than trying to calibrate the parameters in the second half of Table 3, we explore the model's parameter space. In particular, we focus on the dependence of model behavior upon the investment ratio flexibility $\alpha_{i n v}$.

\subsection{Description of behavior types}

If $\alpha_{i n v}=0$, the producer investment ratio $\Gamma_{i n v}$ stay constant, according to Eq. (18). The model possesses in this case the equilibrium described in Section 4.1 (see again Table 4), in which the employment rate is at its equilibrium value $e_{\text {full }}$, the goods inventory is null and the productive capital and the production depend on the investment ratio $\Gamma_{i n v}$, which is fixed. This NEDyM steady state is equivalent to the steady state of a Solow model with a fixed savings ratio.

If the producer investment ratio is allowed to vary, several types of model behavior are possible: 
(a) $\alpha_{i n v}=1.7$
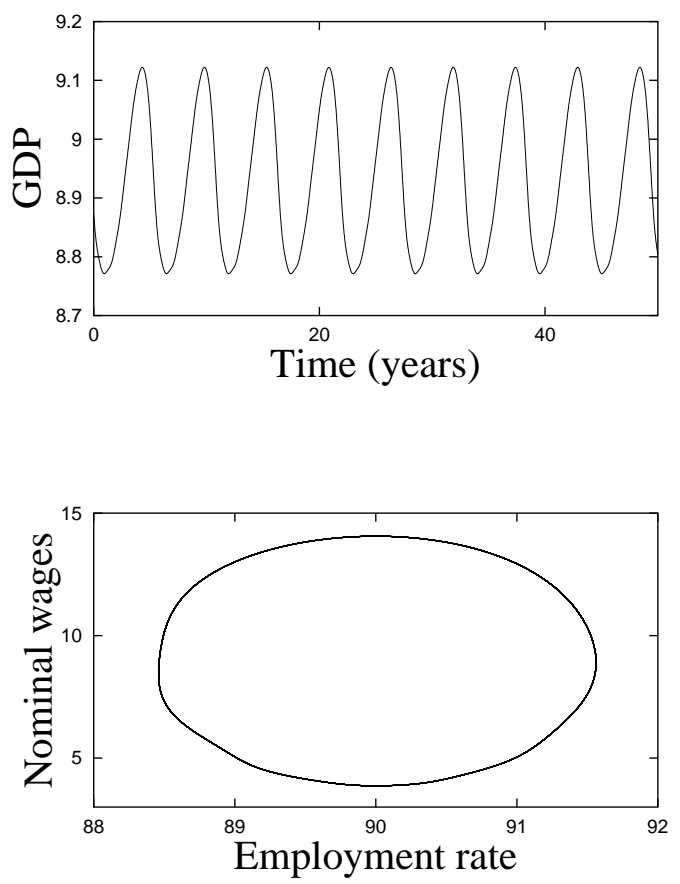

(b) $\alpha_{i n v}=2.5$
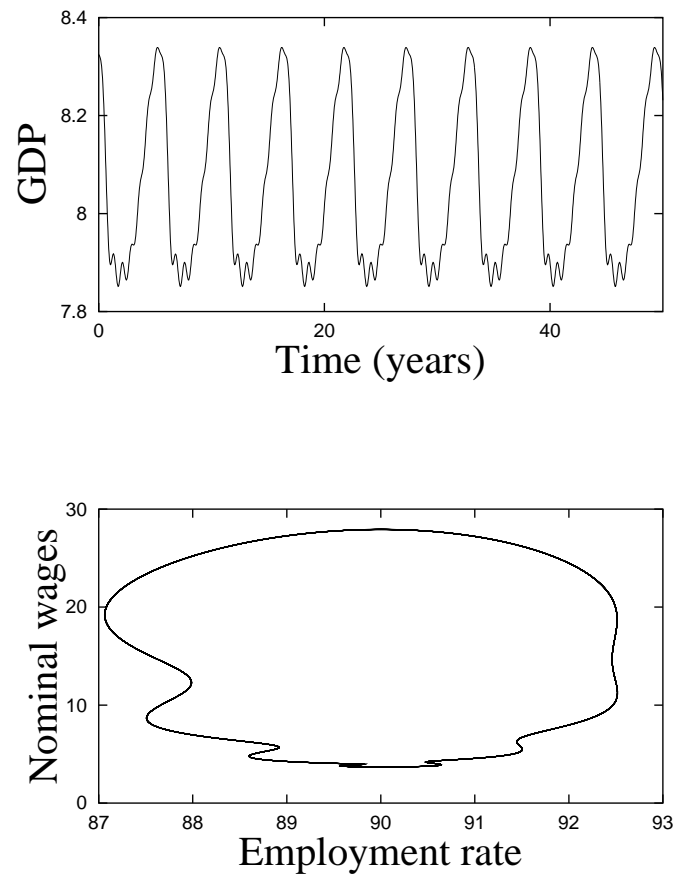

Fig. 2. Model behavior for (a) $\alpha_{i n v}=1.7$ (left column) and (b) $\alpha_{i n v}=2.5$ (right column). Notice the higher amplitude and greater irregularity of the oscillations in the right column.

- Situation 1. If the investment ratio is varying slowly, for example with an investment ratio coefficient $\alpha_{i n v}=1.0, \Gamma_{i n v}$ tends toward its equilibrium value, where the profit per capital unit is equal to the financial standard of profitability $\nu$. The model thus reaches a stable equilibrium. In this case, $\nu$ drives directly the producer investment ratio and thus the level of productive capital and the economic activity. As described in Section 4.1, the NEDyM steady state is then that of a Solow (1956) model with a given savings ratio.

- Situation 2. If the investment ratio coefficient is higher, for example $\alpha_{i n v}=$ 2.5, the model does not reach a stable equilibrium any more but tends to an oscillatory solution, as described in Section 4.2 (see again Fig. 1). The oscillation in the investment ratio $\Gamma_{i n v}$ spreads into the production system, through the investment level. Figure 2 shows the evolution of the model state in this case, for two values of $\alpha_{i n v}$, after the initial transients die out.

The fundamental reason for this oscillatory behavior is that the investment increases when the demand is high and decreases when the demand is low; this response of the investment enhances the demand variations. Like in Harrod (1939), the multiplier-accelerator effect destabilizes the model. 
The reduction in demand, however, does not arise here from Keynesian money hoarding, but from changes in the amount of money involved in the nonproductive closed loop of money between savings and dividends: the saved money is not used for productive investments, because the low level of profits discourages producers from investing, but is redistributed through dividends.

The multiplier-accelerator instability is constrained in our model by two nonlinear effects: (i) by the price increase that is due to the inertia of the supply side, which cannot respond to the increasing demand; and (ii) by the increase in total labor costs $w L$, due to the high employment and the wage increase. These processes reduce the profits per capital unit and oppose the investment instability. Because of the existence of these destabilizing and stabilizing processes, the model reaches an oscillatory behavior. The labor cost constraints are responsible for the turning point in many models (e.g., Rose, 1967; Goodwin, 1967; Skott, 1989); in NEDyM these constraints do not act alone: the role of price inflation is also significant.

An additional feature of the oscillatory solutions in Figs. 1 and 2 is that the employment rate oscillates around its equilibrium value. This behavior is explained by the fact that wages are flexible over the long-term, in spite of inertia. The production, however, does not oscillate around the model's equilibrium value of 9 trillion euros, but around a suboptimal value, understood here as a value lower than the equilibrium value (see $\alpha_{i n v}=2.5$ in Fig. 2b). Comparing Fig. 2a with Fig. 2b, we see that the larger the oscillation's amplitude, the lower the mean state around which the production oscillates. This suboptimality is due to the nonlinearity of the model, especially of the Cobb-Douglas production function: a zero-mean oscillation in one variable can have significant consequences on the mean value of another variable. This "nonlinear rectification mechanism" makes it impossible to express the long-term behavior of our model through relationships between time-averaged values: modeling the short-term dynamics is necessary to understand the long-term behavior.

Not only do the model oscillations increase in amplitude as $\alpha_{i n v}$ increases, but the solutions also become more irregular. In particular, the oscillation in employment rate and wages is quite smooth for $\alpha_{i n v}=1.7$ but develops kinks for $\alpha_{i n v}=2.5$. These kinks are due to the interaction that takes place between the wages (labor market) and the price (goods market) when the oscillation's amplitude is large enough; they affect the production pathway, which exhibits marked irregularity, especially when production is lowest.

- Situation 3. For even higher values of $\alpha_{i n v}$, for example $\alpha_{i n v}=10$, the investment ratio $\Gamma_{i n v}$ may reach its upper or lower bounds, $\gamma_{\max }$ or $\gamma_{\min }$, and new nonlinearities appear, cf. Eq. (18). These constraints can be understood as cash-flow constraints on investment and are imposed here in a rather crude manner. 
(a) $\alpha_{i n v}=10$
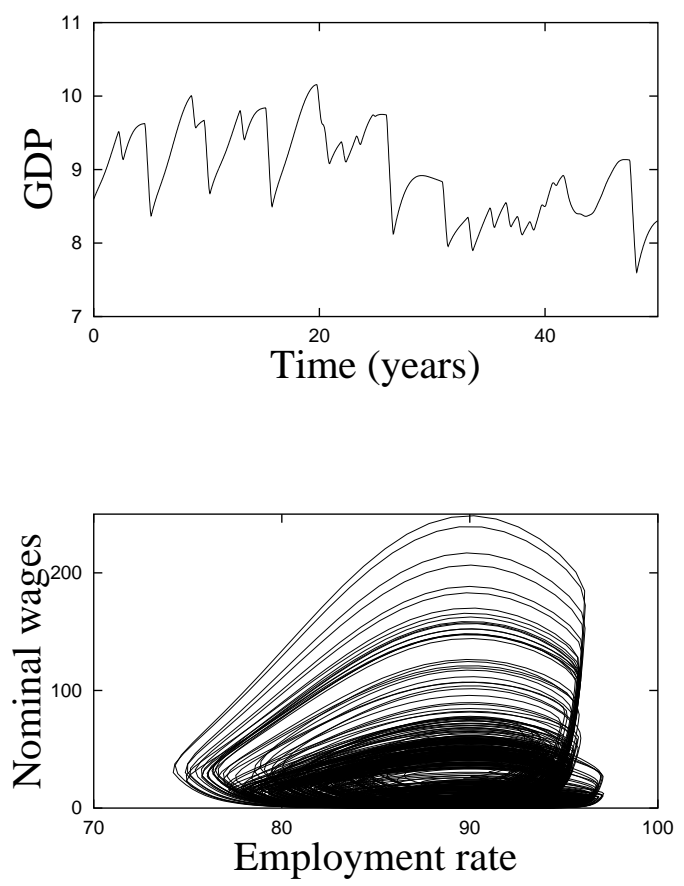

(b) $\alpha_{i n v}=20$
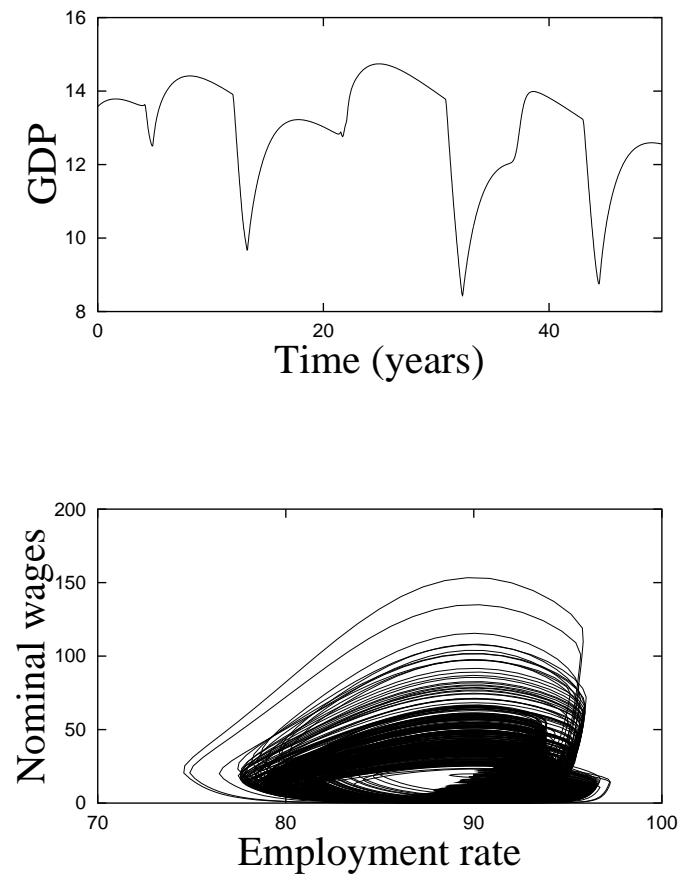

Fig. 3. Model behavior for (a) $\alpha_{i n v}=10$ (left column) and (b) $\alpha_{i n v}=20$ (right column). Notice that the investment ratio $\Gamma_{i n v}$ reaches its upper bound $\gamma_{\max }=0.8$ in the left column, while it reaches both $\gamma_{\max }$ and $\gamma_{\min }=0.0$ in the right column.

Figure 3 shows the effect of these limitations on the long-term behavior of NEDyM solution for two values of $\alpha_{i n v}$. The new nonlinearities associated with the bounds on the investment ratio interact with those already present in Fig. 2. Together, they change qualitatively the model dynamics, which becomes chaotic. In this case, the delayed coupling between a positive (profit-investment) and a negative (labor-cost-investment and priceinvestment) response is no longer alone in driving the oscillations. Because $\Gamma_{i n v}$ approaches its upper bound $\gamma_{\max }$ for $\alpha_{i n v}=10$ and both bounds for $\alpha_{i n v}=20$, the oscillatory mechanism is further affected by two constraints: investment cannot be negative (no early capital retirement is allowed) and investment cannot exceed $80 \%$ of the available flows $\left(p I+\right.$ Div $\left.=\alpha_{F} F\right)$. The nonlinear effect of these constraints perturbs the regular oscillation and contributes to the chaotic behavior.

Even though the model simulations in this situation have unrealistic features, this behavior recalls the results of Day and Shafer (1985), who found chaotic trajectories in a Keynesian model when the induced investment is strong enough. Their induced investment strength can be related to the $\alpha_{i n v}$ value in NEDyM. 


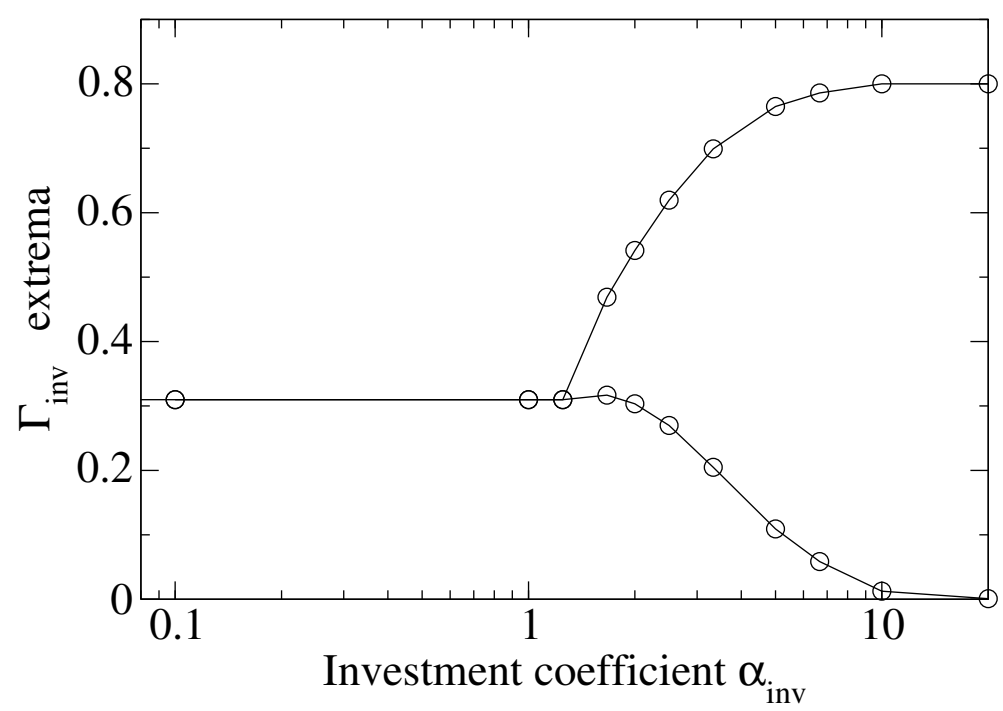

Fig. 4. Range of investment ratio values as a function of the investment coefficient $\alpha_{\text {inv. }}$.

To summarize, the equilibrium of the NEDyM model is locally unstable but the solution trajectories remain bounded due to the interplay of a set of nonlinear feedbacks, namely the decreasing returns in the production function of Eq. (4), the limitation of available labor in Eq. (8), the price and wage responses to market disequilibrium in Eq. (3) and (6), the relationship between price and profits in Eq. (18) and the role of investment constraints in the investment function of Eq. (18).

\subsection{Bifurcation analysis, Lyapunov exponents and power spectra}

We have seen, so far, in a general and qualitative way, that NEDyM solution behavior depends on the parameter values, and particularly on the value of the investment coefficient $\alpha_{i n v}$. Following the general approach of dynamical systems theory (Guckenheimer and Holmes, 1997), we study in the present section this dependence by tracking the changes in qualitative behavior of model solutions as $\alpha_{i n v}$ increases. An application of this approach, called bifurcation analysis, to macroeconomic models appears, for instance, in Benhabib and Nishimura (1979), Barnett and He (2002) or Chiarella et al. (2005).

Figure 4 shows the extrema of the investment ratio oscillation with respect to the investment coefficient $\alpha_{i n v}$. A bifurcation from stationary to timedependent solutions is clearly visible for $1<\alpha_{i n v}<2$. The transition from a stable equilibrium to a stable limit cycle is usually associated with a Hopf 
bifurcation (Guckenheimer and Holmes, 1997). To check whether this is the case here too, we linearized the model around the equilibrium state $\mathbf{X}=\mathbf{X}_{0}$, described in Section 4.1, and we calculated the eigenvalues of this linearized operator. Since the model has 8 state variables (see Table 1 ), there are 8 eigenvalues $\lambda_{i}(i=1, \ldots, 8)$, which depend on $\alpha_{i n v}$. The computation of these eigenvalues for 25 values of $\alpha_{i n v}$, from 0.5 to 2.0, gives the stability of the equilibrium and hence the model solutions' behavior. For all the values of $\alpha_{i n v}$ used, we found four main eigenvalues: the other four are all 3 orders of magnitude smaller than the four main ones and have a negative real part.

The four main eigenvalues are distributed into two pairs of complex conjugate eigenvalues. The first pair $\left(\lambda_{1}, \lambda_{2}\right)$ has an imaginary part that is independent of $\alpha_{i n v}$ and equal to $-0.3210^{-2}$, which corresponds to an oscillation with a 5.5-year period, as observed in the model simulations (Figs. 1, 2, or 3). The real part of $\lambda_{1}$ and $\lambda_{2}$ is a linearly increasing function of $\alpha_{i n v}$, at least in the range we studied. This straight line crosses the value $\operatorname{Re}(\lambda)=0$ at $\alpha_{i n v}=1.39$, where the equilibrium is neutral. When $\alpha_{i n v}<1.39$, the real parts are negative, the equilibrium is stable, and this pair of eigenvalues corresponds to a damped oscillation with a 5.5-year period. When $\alpha_{i n v}>1.39$, the real parts are positive, the equilibrium is unstable and this pair of eigenvalues corresponds to a growing oscillation. This oscillation is bounded and tends to a limit cycle, because of the model's nonlinearity. This behavior corresponds to a Hopf bifurcation of the model at $\alpha_{i n v}=1.39$.

The second pair $\left(\lambda_{3}, \lambda_{4}\right)$ is independent of $\alpha_{i n v}$ altogether: its real part is $-0.6610^{-3}$, which corresponds to a characteristic decay time of $4.15 \mathrm{yr}$; its imaginary part is $-0.2310^{-1}$, corresponding to an oscillation with a 276 -day period. This oscillation arises from labor-market dynamics and the Phillips curve, Eq. (6); it is related to the Goodwin (1967) cycle.

For high values of $\alpha_{i n v}$, the model trajectories suggest the existence of chaotic behavior. To verify this visual evidence, we computed the model's Lyapunov exponents (Ghil and Childress, 1987; Guckenheimer and Holmes, 1997; Sprott, 2003), from the state transition matrix. The singular values of this matrix calculated through a singular vector decomposition - yield the Lyapunov exponents $\Lambda_{i}$. If at least one $\Lambda_{i}$ is strictly positive, there are perturbations that increase exponentially with time and the system exhibits sensitivity to its initial state. In this latter case, the model is chaotic.

We calculated the Lyapunov exponents of NEDyM for three values of the investment flexibility: $\alpha_{i n v}=0.1$ for which the model is stable; $\alpha_{i n v}=2$, for which the model tends to a limit cycle; and $\alpha_{i n v}=10$, for which the model exhibits complex dynamics. For $\alpha_{i n v}=0.1$, only $\Lambda_{1}$ is null, while the other seven $\Lambda_{i}$ are strictly negative; this corresponds to the model's insensitivity to changes in the monetary unit. For $\alpha_{i n v}=2$, there is a second $\Lambda_{i}=0$, which 


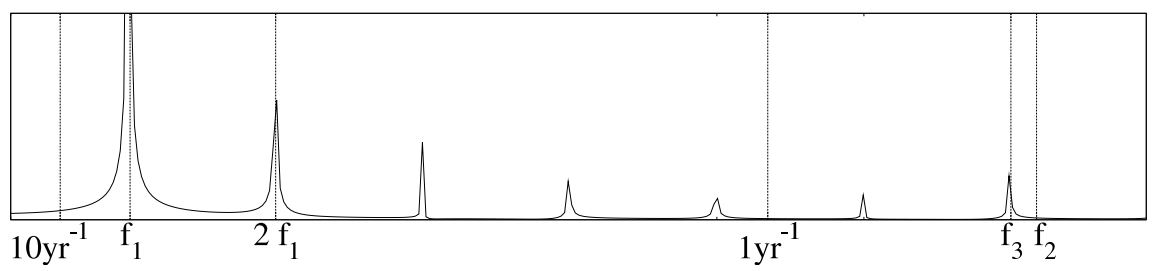

Fig. 5. Power spectrum of production evolution, $Y=Y(t)$, for $\alpha_{i n v}=2.5$, with arbitrary vertical units. Calculated by Fast Fourier Transform (FFT) from the model limit cycle, with time series of at least 3000 years. The frequency of the seventh harmonic of the main frequency is indicated as $f_{3}$, and the frequency of the second pair of eigenvalues as $f_{2}$.

corresponds to the tangent direction along the limit cycle. For $\alpha_{i n v}=10$, the four largest Lyapunov exponents are strictly positive and lie between 0.09 and $0.11 \mathrm{yr}^{-1}$. There exist, in this case, infinitesimal perturbations that cause the model's trajectories to diverge with a characteristic time of about 10 years. The model is therefore chaotic for large enough $\alpha_{i n v}$ and no economic forecast would be able to provide an accurate and reliable prediction over more than 10 years for such values of the investment flexibility.

To study further the business cycle reproduced by the model, we computed the power spectrum of several model variables, for $\alpha_{i n v}=2.5$. The results are plotted in Fig. 5 for one of the diagnostic variables, production $Y$; results for other model variables are quite similar (not shown). This figure shows an oscillation with a period of $T_{1}=5.4 \mathrm{yr}$, which is close to the period given by the first pair of eigenvalues, and a few harmonics of decreasing amplitude. No significant variability is found for periods larger than 6 years. The period, as well as the amplitude of nonlinear oscillations depends on the parameters; this explains why the observed main period $T_{1}=5.4 \mathrm{yr}$ differs slightly from its value at the bifurcation point, $\alpha_{i n v}=1.39$, namely $T^{\prime}=5.5 \mathrm{yr}$.

An interesting phenomenon of frequency locking (Winfree, 1980; Ghil, 1994) occurs in NEDyM: for $\alpha_{i n v}=2.5$, and for a wide range of value around it, the frequency of the second pair of eigenvalues, $f_{2}=1 / 276 \mathrm{dy}^{-1}$, does not appear at all in the power spectrum. The seventh harmonic of the main frequency, $f_{3}=7 f_{1}=7 / 5.4 \mathrm{yr}^{-1}=1 / 283 \mathrm{dy}^{-1}$, however, is very close to it, and exhibits a larger amplitude than previous harmonics, suggesting that the second frequency $f_{2}$ is practically locked on the seventh harmonic of the main one, at the frequency $f_{3}$. As already stated in Section 4.2 , this latter frequency may also be locked in the real world on the annual economic cycle, amplifying the amplitude of the latter (Jin et al., 1994, 1996; Tziperman et al., 1994). 


\section{Concluding remarks}

\subsection{Summary}

In this paper, we have pursued an endogenous approach to modeling economic cycles. In NEDyM, as suggested theoretically by Invernizzi and Medio (1990), business cycles arise from inertial effects (see Sections 2, 3 and 4.2), namely from delays in the adjustment of price, wages and investment decisions, even though the model's long-term equilibrium is neo-classical in nature. Similar delay effects give rise to oscillations in both biological (May, 1974) and climatological (Bhattacharya et al., 1982) settings.

The business cycles generated by this model, subject to an assumption of managerial control of investment decisions, reproduce several key features of observed cycles: (i) their four phases, namely (a) recovery, (b) expansion with inflation, full employment and decrease in the profit rate, (c) contraction with deflation, and (d) depression, unemployment and restoration of the profit rate; (ii) the typical leads and lags among major economic indicators (Zarnovitz, 1985; King and Watson, 1996); (iii) the mean period of 5-6 years; and (iv) the cycle's asymmetry (Kontolemis, 1997), with a longer expansion phase and a more rapid contraction.

The key trigger of these cycles is basically the multiplier-accelerator effect that occurs when investment flexibility exceeds a certain threshold. The instability that leads to the cycles is indeed generated by the interplay between shortterm Keynesian effects, with delays in price adjustments, on the one hand, and supply-side and labor-availability constraints, on the other: as investment increases, the demand increases more rapidly than the production capacity and the employment rate reaches high values, leading to inflation of price and wages, reduced profits per capital unit, and thus reduced investment. The interaction of these processes creates an oscillatory behavior, whose amplitude increases with the investment flexibility. In our model, however, fluctuations in demand do not arise from a Keynesian hoarding of money but from the nonproductive, closed money loop between consumer savings and dividends that sets in when a low profit rate discourages producers from investing.

When investment flexibility increases, the amplitude of the business cycle is greater and financial constraints on investment come into play; investment cannot keep responding to the profit signal and this newly binding constraint generates complex dynamics and chaotic behavior. This type of behavior is most likely to be observed at times when several resource constraints also become binding; along with financial constraints, these can include limitation on natural resources or labor availability. 


\subsection{Discussion}

Our model results do not pretend to resolve the controversy between those who affirm (Baumol and Benhabib, 1989) and those who deny (Brock et al., 1991) the existence of chaos in macroeconomic data. We agree, in fact, with those who think that chaotic behavior in economic series might not be detectable by time series analysis alone, because of the shortness of the series (Jarsulic, 1993); compare similar statements for climatic time series in Grassberger (1986) and Ghil (1994). We simply meant to provide a consistent framework for discussing the various views of long-term economic dynamics and how they may change the assessment of the costs and benefits of policies proposed to cope with the issues of climate change or energy transitions ${ }^{9}$. The NEDyM model appears, indeed, to be a useful tool in studying how this cost-benefit balance may change if the economy exhibits endogenous fluctuations, instead of always staying on a balanced-growth pathway.

Introducing various types of inertia into the Solow model allowed us to gain useful insights into economic dynamics. Indeed, while Solow (1956) showed that perfect labor-capital substitution allows for the existence of steady-state growth pathways, we follow Nikaido (1996) in showing that, even with factor substitution, inertia and adjustment delays may destabilize these pathways, leading to short-term fluctuations or even chaotic behavior. Proceeding further along this path, we show that endogenous variability is not restricted to models with Harrodian (demand-led) investment function but can also arise from profit-led investment functions, and manage to reproduce business cycles with realistic characteristics that originate from these processes.

Our conclusion is that, for a simple economy without endogenous technical progress and demographic growth, complex behavior in the economic system can be attributed to deterministic endogenous factors, instead of the random exogenous shocks of "real-cycle" theory (Kydland and Prescott, 1982). This difference matters in the assessment of the long-term impacts of environmental shocks or mitigation policies. In particular, in this framework, nonlinear rectification mechanisms make it impossible to model the slowly evolving component of economic dynamics through relationships between time-averaged values: changes in the short-term dynamics do modify the averaged value of the variables along the trajectory, even though the latter may evolve around the unstable equilibrium. As a consequence, the short-term processes cannot be neglected in the assessment of long-term economic properties, as can be done in the real-cycle framework.

\footnotetext{
9 See for instance the preliminary results on the economic effects of extreme events in Hallegatte et al. (2006).
} 


\section{Acknowledgments}

The authors wish to acknowledge Alain Lahellec for his help in the analysis of the dynamic system that governs our model. Carl Chiarella, Reyer Gerlagh, and two anonymous reviewers have made valuable comments and suggestions on earlier versions of this paper. This research was supported by the European Commission's Project No. 12975 (NEST) "Extreme events: Causes and consequences (E2-C2)".

\section{References}

Aglietta, M., Rebérioux, A., 2004. Dérives du Capitalisme Financier. Bibliothèque Albin Michel Economie.

Arrow, K., 1989. Workshop on the economy as an evolving complex system: Summary. In P. Anderson et al. (Eds.), The Economy as an Evolving Complex System, Addison-Wesley, New-York, 275-282.

Asada, T., Chen, P., Chiarella, C., Flaschel, P., 2004. Keynesian dynamics and the wage-price spiral: A baseline disequilibrium model. School of Finance and Economics, University of Technology, Sydney, Working Paper no. 139.

Barnett, W., He, Y., 2002. Bifurcations in macroeconomic models. Innovations in Macrodynamics, S. Dowrick, R. Pitchford, S. Turnovsky (Eds.), Cambridge University Press.

Baumol, W., Benhabib, J., 1989. Chaos: Significance, mechanism, and economic applications. Journal of Economic Perspectives 3 (1), 77-105.

Benhabib, J., Nishimura, K., 1979. The Hopf-bifurcation and the existence of closed orbits in multi-sectoral models of optimal economic growth. Journal of Economic Theory 21, 421-444.

Berle, A., Means, G., 1932. The Modern Corporation and Private Property. New-York, Harcourt, Brace and World.

Bhattacharya, K., Ghil, M., Vulis, I. L., 1982. Internal variability of an energybalance model with delayed albedo effects. J. Atmos. Sci. 39, 1747-1773.

Brock, W., Hsieh, D., Lebaron, B., 1991. Nonlinear Dynamics, Chaos and Instability. MIT Press, Cambrdige.

Calvo, G., 1983. Staggered prices in a utility-maximizing framework. Journal of Monetary Economics 12, 383-398.

Chiarella, C., 1988. The cobweb model, its instability and the onset of chaos. Economic Modelling 5 (4), 377-384.

Chiarella, C., Flaschel, 2000. The Dynamics of Keynesian Monetary Growth. Cambridge University Press.

Chiarella, C., Flaschel, P., Franke, R., 2005. Foundations for a Disequilibrium Theory of the Business Cycle. Cambridge University Press. 
Cobb, C., Douglas, P., 1928. A theory of production. The American Economic Review 18 (1), 139-165.

Copeland, T., Weston, J., 2003. Financial Theory and Corporate Policy. Third Edition, Pearson Education International, Prentice Hall, Upper Saddle River, New Jersey, USA.

Day, R., 1979. Cautious optimizing. in J. Roumasset et al. (Eds.), Risk Uncertainty and Agricultural Development, New-York, Agricultural Development Council, ch. 7.

Day, R., 1982. Irregular growth cycles. American Economic Review 72, 406414.

Day, R., Shafer, W., 1985. Keynesian chaos. Journal of Macroeconomics 7 (3), 277-295.

Eurostat, 2002. Economic portrait of the European Union 2001. Panorama of the European Union, European Commission.

Frisch, R., 1933. Propagation Problems and Impulse Problems in Dynamic Economics. Economic Essay in honor of Gustav Cassel, London: George Allen and Unwin.

Galí, J., 2000. The return of the Phillips curve and other recent developments in business cycle theory. Spanish Economic Review 2 (1), 1-10.

Gelb, A., 1974. Applied Optimal Estimation. MIT Press, Cambridge, MA, 374 pp.

Ghil, M., 1994. Cryothermodynamics: the chaotic dynamics of paleoclimate. Physica D 77, 130-159.

Ghil, M., 1997. Advances in sequential estimation for atmospheric and oceanic flows. J. Meteor. Soc. Japan 75, 289-304.

Ghil, M., Childress, S., 1987. Topics in Geophysical Fluid Dynamics: Atmospheric Dynamics, Dynamo Theory and Climate Dynamics. Springer-Verlag, New York/Berlin/London/Paris/ Tokyo, 485 pp.

Goodwin, R., 1951. The non-linear accelerator and the persistence of business cycles. Econometrica 19, 1-17.

Goodwin, R., 1967. A growth cycle. In C. Feinstein (Ed.), Socialism, Capitalism and Economic Growth, Cambridge University Press, Cambridge.

Grandmont, J.-M., 1985. On endogenous competitive business cycles. Econometrica 5, 995-1045.

Grassberger, P., 1986. Do climatic attractors exist? Nature 323, 609-612.

Guckenheimer, J., Holmes, P., 1997. Nonlinear Oscillations, Dynamical Systems, and Bifurcations of Vector Fields. 3rd ed., Springer-Verlag, New York.

Hallegatte, S., Hourcade, J.-C., Dumas, P., 2006. Why economic dynamics matter in the assessment of climate change damages: illustration on extreme events. accepted by Ecological Economics.

Harrod, R., 1939. An essay on dynamic economic theory. Economic Journal 49, 1433.

Hicks, J., 1950. The cycle in outline. A Contribution to the Theory of the Trade Cycle, Oxford, Oxford University Press, Ch. 8, 95-107.

Invernizzi, S., Medio, A., 1990. On lags and chaos in economic dynamic models. 
Journal of Mathematical Economics 20, 521-550.

IPCC, 2001. Climate Change 2001 : Impacts, Adaptation and Vulnerability [McCarthy, JJ, Canziani, O.F., Leary, N.A., Dokken, D., White, K.S. (Eds.)]. Cambridge University Press, Cambridge, United Kingdom and NewYork, NY, USA.

Jarsulic, M., 1993. A nonlinear model of the pure growth cycle. Journal of Economic Behavior and Organization 22 (2), 133-151.

Jensen, M., 1986. Agency costs of free cash flow, corporate finance and takeovers. American Economic Review 76, 323-329.

Jin, F.-F., Neelin, J., Ghil, M., 1994. El Niño on the devil's staircase: Annual subharmonic steps to chaos. Science 264, 70-72.

Jin, F.-F., Neelin, J., Ghil, M., 1996. El Niño/Southern Oscillation and the annual cycle: Subharmonic frequency-locking and aperiodicity. Physica D 98, 442-465.

Kaldor, N., 1940. A model of the trade cycle. Economic Journal 50, 78-92.

Kalecki, M., 1937. A theory of the business cycle. Review of Economic Studies 4, 77-97.

Kalnay, E., 2003. Atmospheric Modeling, Data Assimilation and Predictability. Cambridge Univ. Press, Cambridge/London, UK, 341 pp.

Kendrick, D., 2005. Stochastic control for economic models: past, present and the paths ahead. J. Econ. Dyn. \& Control 29, 3-30.

King, R., Watson, M., 1996. Money, prices, interest rates and the business cycle. The Review of Economics and Statistics 78 (1), 35-53.

Kontolemis, Z., 1997. Does growth vary over the business cycle? Some evidence from the G7 countries. Economica 64 (255), 441-460.

Kydland, F., Prescott, E., 1982. Time to build and aggregate fluctuations. Econometrica 50 (6), 1345-1370.

Lucas, R., 1967. Adjustment costs and theory of supply. Journal of Political Economy 75, 321-334.

Lucas, R., 1975. An equilibrium model of the business cycle. The Journal of Political Economy 83 (6), 1113-1144.

Malanotte-Rizzoli, P., 1996. Modern Approaches to Data Assimilation in Ocean Modeling. Elsevier Publishing Co., 455 pp.

Malinvaud, E., 1982. Wages and unemployment. The Economic Journal 92 (365), 1-12.

May, R., 1974. Stability and Complexity in Model Ecosystems. Princeton Landmarks in Biology, Princeton University Press, Princeton.

Modigliani, F., Miller, M., 1958. The cost of capital, corporation finance and the theory of investment. American Economic Review 48, 261-97.

Nikaido, H., 1996. Prices, Cycles, and Growth. MIT Press, Cambridge, MA, $285 \mathrm{pp}$.

Phillips, A., 1958. The relation between unemployment and the rate of change of money wage rates in the United Kingdom, 1862-1957. Economica 25 (100), 283-299.

Pigou, A., 1947. Economic progress in a stable environment. Economica 
14 (55), 180-188.

Reichlin, P., 1986. Equilibrium cycles in an overlapping generations model with production. Journal of Economic Theory 40, 89-102.

Roe, M. J., 1994. Strong Managers, Weak Owners: the Political Roots of American Corporate Finance. Princeton University Press.

Rose, H., 1967. On the nonlinear theory of employment cycle. Review of Economic Studies 34, 153-173.

Rosser, J. B., 1999. On the complexities of complex economic dynamics. The Journal of Economic Perspectives 13 (4), 169-192.

Samuelson, P., 1939. A synthesis of the principle of acceleration and the multiplier. Journal of Political Economy 47, 786-797.

Schinasi, B., 1981. A nonlinear dynamic model of short-term fluctuation. Review of Economic Studies 48, 649-656.

Skott, P., 1989. Effective demand, class struggle and cyclical growth. International Economic Review 30 (1), 231-247.

Slutsky, E., 1927. The summation of random causes as a source of cyclic processes, III(1). Conjuncture Institute, Moscow, Reprinted in Econometrica $5,105-146$.

Solow, R., 1956. A contribution to the theory of economic growth. The Quarterly Journal of Economics 70 (1), 65-94.

Solow, R., 1988. Growth theory and after. The American Economic Review 78 (3), 307-318.

Sprott, J., 2003. Chaos and Time-Series Analysis. Oxford University Press, $528 \mathrm{pp}$.

Süssmuth, B., 2002. National and Supranational Business Cycles (1960-2000): A Multivariate Description of Central G7 and EURO15 NIPA Aggregates. CESifo Working Paper Series No. 658.

Tobin, J., 1969. A general equilibrium approach to monetary policy. Journal of Money, Credit and Banking 1, 15-29.

Tziperman, E., Stone, L., Cane, M., Jarosh, H., 1994. El Niño chaos: Overlapping of resonances between the seasonal cycle and the Pacific oceanatmosphere oscillator. Science 264, 72-74.

Wang, P.-F., Wen, Y., 2004. Endogenous money of sticky prices? - comment on monetary non-neutrality and inflation dynamics. J. Econ. Dyn. \& Control 29 (8), 1361-1383.

Wen, Y., 2002. The business cycle effects of christmas. Journal of Monetary Economics 49, 1289-1314.

Winfree, A., 1980. The Geometry of Biological Time. Springer-Verlag, New York, $530 \mathrm{pp}$.

Yun, T., 1996. Nominal price rigidity, money supply endogeneity, and business cycle. Journal of Monetary Economics 37, 345-370.

Zarnovitz, V., 1985. Recent work on business cycle in historical perspective: A review of theories and evidence. Journal of Economic Literature 23 (2), $523-580$. 